\title{
DA COEXISTÊNCIA À CONVIVÊNCIA COM O OUTRO: entre o multiculturalismo e a interculturalidade
}

\author{
Ana Maria D'Ávila Lopes*
}

\begin{abstract}
Há séculos, Homero afirmou ser a civilidade a característica que distingue os homens dos animais. Os Ciclopes, afirmava o poeta grego, eram considerados monstros selvagens não porque não praticavam a navegação, mas porque ignoravam a hospitalidade. Hoje, mais de vinte séculos depois, a Interculturalidade busca resgatar a virtude da civilidade como forma de garantir a convivência pacífica entre maiorias e minorias, superando, assim, as limitações do Multiculturalismo e sua proposta da tolerância. Nesse contexto, o objetivo deste trabalho é defender a virtude da civilidade como pressuposto para a garantia efetiva dos direitos fundamentais de todos os membros de uma sociedade pluricultural.
\end{abstract}

Palavras-chave: Tolerância; Multiculturalismo; Interculturalidade; Civilidade; Minorias.

\section{Introdução}

$\mathrm{Na}$ atualidade, a diversidade cultural constitui marca inegável dos mais de 190 Estados-membros da ONU. Praticamente não há, hoje, Estado que não possa ser considerado multinacional ou multiétnico. ${ }^{1}$

Nesse contexto, como garantir a convivência pacífica entre culturas diferentes? Adeno Addis ${ }^{2}$ responde a esse interrogante com outra pergunta: quando um casamento não dá certo, as pessoas se

\footnotetext{
* Mestre e Doutora em Direito Constitucional pela Universidade Federal de Minas Gerais - UFMG. Professora do Programa de Pós-Graduação em Direito da Universidade de Fortaleza - UNIFOR. Membro Efetivo da Câmara de Assessoramento e Avaliação - Área Ciências Sociais - da Fundação Cearense de Apoio ao Desenvolvimento Científico e Tecnológico. Bolsista do CNPq. Fortaleza/Brasil. ${ }^{1}$ Cf. KYMLICKA, Will. Ciudadanía multicultural, p. 14 e ss.

${ }^{2}$ ADDIS, Adeno. "On human diversity and the limits of toleration".
} 
separam, mas é isso possível no caso de grupos culturais minoritários existentes no interior de um Estado? A separação das minorias apresentase como pouco prática e perigosa. É pouco prática porque muitos grupos minoritários não ocupam uma unidade territorial continua. É também perigosa porque pode culminar na criação de "semi-estados" dentro de um mesmo Estado, sendo que, ao longo do tempo, podem desenvolver pretensões de autodeterminação muitas vezes de caráter violento.

Como, então, garantir a harmonia nas sociedades culturalmente diversas? Trata-se de uma discussão que não é nova, mas que se remonta ao fim do domínio da Igreja nos séculos XVI-XVII, quando, pela primeira vez, cogitou-se a possibilidade do reconhecimento de direitos às minorias.

Nesse contexto, a tolerância volta a ser invocada pelos multiculturalistas como o melhor meio para proteger as minorias. Contudo, constata-se que, apesar dos seus méritos, a tolerância padece de limitações para promover a virtude da civilidade entre os grupos majoritários e minoritários que compõem a sociedade política globalizada.

É esse, precisamente, o objeto do presente trabalho: identificar as limitações da tolerância na criação de vínculos de solidariedade nas sociedades culturalmente diversas, partindo-se da concepção da civilidade como pressuposto para a consolidação e o respeito aos direitos fundamentais de todos os seres humanos, conforme o defendido pela Interculturalidade.

Paratal, inicialmente será exposta a diferença entre Multiculturalismo e Interculturalidade. Seguidamente, as boas e más razões da tolerância serão apresentadas. Finalmente, as limitações da tolerância para a promoção da virtude da civilidade serão analisadas.

\section{Do Multiculturalismo à Interculturalidade para fortalecer a civilidade}

O Multiculturalismo - também chamado de pluralismo cultural ou cosmopolitismo - busca que se reconheça e se respeite a diversidade cultural presente em todas as sociedades.

A expressão multiculturalismo designa, originariamente, a coexistência de formas culturais ou de grupos caracterizados por culturas diferentes no seio das sociedades modernas (...). Existem diferentes noções de multiculturalismo, nem todas no sentido "emancipatório". O termo apresenta as 
mesmas dificuldades e potencialidades do conceito de "cultura", um conceito central das humanidades e das ciências sociais e que, nas últimas décadas, se tornou terreno explícito de lutas políticas. ${ }^{3}$

Mikhaël Elbaz ${ }^{4}$ ensina que Multiculturalismo é um conceito e uma ideologia, cuja polissemia somente pode ser entendida no âmbito da desestruturação da narração nacional, sob os efeitos da globalização.

A Interculturalidade, por sua vez, é um conceito que, embora tenha também surgido como reação dos estados nacionais ao processo de uniformização cultural decorrente da globalização, difere substancialmente do Multiculturalismo.

Virgilio Alvarado ${ }^{5}$ distingue claramente os dois conceitos ao afirmar que, enquanto o Multiculturalismo propugna a coexistência num mesmo espaço social de culturas diferentes sob o princípio da tolerância e do respeito à diferença, a Interculturalidade, ao pressupor como inevitável a interação entre essas culturas, propõe um projeto político capaz de estabelecer um diálogo entre elas, como forma de garantir uma real convivência pacífica. ${ }^{6}$

Em favor da Interculturalidade, Alvarado aponta algumas das suas principais características:

a) é um conceito dinâmico que supera o Multiculturalismo ao reconhecer a sociedade como um espaço de permanente interação;

b) propugna não apenas o respeito à diversidade cultural, mas a necessidade da convivência e troca de experiências;

c) procura recriar as culturas existentes, reconhecendo que se encontram em permanente transformação;

d) propõe uma nova síntese cultural, o que implica a reelaboração dos modelos culturais preconcebidos;

e) pressupõe a interação entre as culturas que, embora muitas vezes tensa, pode ser regulada.

Nesse sentido, Alvarado afirma que o Estado não está apenas obrigado a criar e fortalecer mecanismos de resgate e respeito da identidade cultural dos diferentes grupos que o compõem, como assim o defende o

\footnotetext{
${ }^{3}$ SANTOS, Boaventura de Sousa; NUNES, João Arriscado. Introdução: para ampliar o cânone do reconhecimento, da diferença e da igualdade.

${ }^{4}$ ELBAZ, Mikhaël. "El inestimable vínculo cívico en la sociedad-mundo", p. 27.

${ }^{5}$ ALVARADO, Virgilio. "Políticas públicas e interculturalidad", p. 33 e ss.

${ }^{6}$ FULLER, Norma. "Introducción", p. 15.
} 
Multiculturalismo, mas deve também adotar sistemática e gradualmente espaços e processos de interação positiva entre as diferentes culturas, com a finalidade de abrir e gerar relações de confiança, de reconhecimento mútuo, de comunicação, diálogo e debate, aprendizagem e intercâmbio, cooperação e convivência, sendo esse, precisamente, o objeto da Interculturalidade.

Para a Interculturalidade, a simples coexistência entre os membros de uma sociedade não é suficiente para a garantia dos seus direitos fundamentais. O sentimento de pertença, o submetimento às leis em prol do bem comum e a solidariedade entre todas as pessoas constituem pré-requisitos para o sucesso de toda comunidade, conforme já tinha sido apontado pelos gregos na formulação da virtude da civilidade.

Los griegos naturalmente espirituales y valerosos, habían sido civilizados desde una hora temprana por los reyes y las colonias que vinieron a su país del Egipto [...] lo mejor que les enseñaron los egipcios fue hacerse dóciles y a dejarse formar por las leyes que les inspiraron amor al bien público [...] los griegos estaban enseñados a mirarse recíprocamente con interés, y a mirar a sus familiares como parte de un gran cuerpo del Estado [...]. La palabra civilidad no significaba solamente entre los griegos la afabilidad y la mutua deferencia que hacen a los hombres sociables; el hombre civil no era otra cosa más que un buen ciudadano, que se considera siempre como miembro del Estado, y que se deja llevar por las leyes conspirando con ellas al bien público, sin emprender nada contra ninguno [...] La idea de libertad que inspiraba semejante conducta era admirable. Porque la libertad, tal como la entendían los griegos, era una libertad sometida a la ley, es decir, subordinada a la razón y a la conveniencia pública, reconocidas por todo el pueblo. ${ }^{7}$

Raynauld y Rials $^{8}$ ensinam que, para os gregos, a cidade representava o espaço propriamente humano entre o mundo selvagem, que é seu limite inferior, e o mundo divino, que marcava seu limite superior inacessível. É na cidade que o homem realiza sua natureza política, sua autarquia, sua capacidade de se dar a si mesmo suas próprias leis, sendo o diálogo com o outro indispensável, pois viver em sociedade exige a comunicação com os outros.

\footnotetext{
${ }^{7}$ BOSSUET, Jacques. Bégnine. Discurso sobre la historia universal, p. 291.

${ }^{8}$ RAYNAULD, Philippe; RIALS, Sthephane. Diccionario Akal de Filosofía Política, p. 101.
} 
Isócrates, por exemplo, definia o homem por sua capacidade de falar identificada com sua civilidade e seu poder de criar cidades e viver nelas politicamente:

De todos nuestros otros caracteres, ninguno nos distingue de los animales. Incluso somos inferiores a muchos en lo que respecta a la velocidad, la fuerza, y otras facilidades de acción. Pero por haber recibido el poder de persuadirnos mutuamente y de establecer en nosotros mismos el objeto de nuestras decisiones, no sólo nos hemos librado de la vida salvaje, sino que nos hemos reunido para construir ciudades; hemos fijado leyes; hemos descubiertos artes; y la palabra es lo que nos ha permitido llevar a buen fin casi todos nuestros inventos. La palabra fijó los límites legales entre la justicia y la injusticia, entre el mal y el bien; si esta separación no se hubiese establecido, seguiríamos siendo incapaces de habitar unos junto a otros. ${ }^{9}$

O diálogo constitui, pois, a diferença fundamental entre a proposta do Multiculturalismo e a Interculturalidade,
Mientras que en el multiculturalismo la palabra clave es tolerancia, en la interculturalidad "la palabra clave es diálogo. La interculturalidad reasume en parte el multiculturalismo, en el sentido de que para dialogar hay que presuponer respeto mutuo y condiciones de igualdad entre los que dialogan". ${ }^{10}$

Nesse contexto, a tolerância emerge como o primeiro passo para a construção de uma sociedade pacífica, sendo, entretanto, necessário o fortalecimento da virtude da civilidade, o que será alcançado por meio do diálogo livre e em igualdade de condições entre maiorias e minorias, conforme explicitado a seguir.

\section{O primeiro passo: tolerar para coexistir}

Marcílio de Pádua é considerado pela maioria da doutrina como o precursor da teoria política da tolerância ${ }^{11}$, desenvolvida com o objetivo de defender a liberdade religiosa e o fim da hierarquia absoluta da Igreja e do Estado. No seu livro "O Defensor da Paz", escrito em 1324², Marcílio

\footnotetext{
${ }^{9}$ ISÓCRATES. Discursos, p. 43.

${ }^{10}$ TUBINO, Fidel. "Entre el multiculturalismo y la interculturalidad: más allá de la discriminación positiva", p. 74.

${ }^{11}$ BOBBIO, Norberto; MATTEUCCI, Nicola; PASQUINO, Gianfranco. Dicionário de política, p. 1246.

12 PÁDUA, Marcílio de. O defensor da paz.
} 
ensina que a Bíblia convida a ensinar e a convencer, e não a impor nem a punir. A consciência não pode ser coagida, sendo que a fé imposta não traz a salvação espiritual.

Essas ideias foram retomadas séculos depois por diversos autores (Thomas More, Pico della Mirándola, Espinosa, Pufendorf, Grócio, dentre outros), destacando-se John Locke que, em 1685, escreveu a "Carta sobre a Tolerância"13. No texto, que viria a ser tornar peça fundamental do laicismo, Locke defendeu categoricamente a separação entre o Estado e a Igreja, e a tolerância dos que professavam diferentes religiões.

O princípio da tolerância afirmou-se plenamente no século XVIII graças ao Iluminismo e ao Racionalismo. Nessa época destaca-se o "Tratado sobre a tolerância" escrito em 1763 por Voltaire ${ }^{14}$, que buscou demonstrar que a intolerância religiosa não é defendida nem pela tradição cristã nem pela judaica.

Evidencia-se, assim, que os problemas derivados da diversidade cultural e a invocação do princípio da tolerância para amenizá-la não são recentes. No entanto, constata-se também que, nunca antes como hoje, a tolerância com o diferente tem se tornado crucial para a construção da paz na sociedade mundial globalizada e a consolidação dos Estados democráticos.

Trata-se de um fenômeno derivado de dois acontecimentos que transformaram fortemente o panorama sócio-político mundial do final século $X X^{15}$ : a desintegração da União Soviética e o fim do Comunismo. Essas clausuras históricas despertaram antigas rivalidades étnicas no Leste Europeu, mantidas sob controle pelo regime comunista fortemente autoritário. Provocaram, também, o fim da bipolaridade política mundial e a extinção dos dois super-poderes (Estados Unidos e União Soviética), que não apenas reprimiam drasticamente qualquer foco de conflito interno, mas auxiliavam seus respectivos Estados aliados a aplacarem seus próprios conflitos internos.

Com o fim desses regimes fortemente controladores, as minorias, que tinham sido silenciadas por décadas, puderam sair à luz para clamar por seus direitos.

\footnotetext{
${ }^{13}$ LOCKE. John. Carta sobre a tolerância.

${ }^{14}$ VOLTAIRE. Tratado sobre a tolerância.

${ }^{15}$ ADDIS, op. cit., p. 115-118.
} 
Hoje, em pleno século XXI, as minorias vêm paulatinamente se libertando da opressão que as invisibilizava, assumindo o protagonismo do seu destino. Trata-se de um fenômeno que tem sido potencializado pelo fenômeno da globalização e os avanços dos meios de comunicação e de transporte que, por sua vez, têm favorecido seu deslocamento em busca de melhores condições de vida, formando um grande contingente de migrantes cujos direitos devem ser preservados.

Nesse novo contexto mundial, o princípio da tolerância volta a emergir como uma alternativa para a construção de uma sociedade pacífica. Apesar de a tolerância ter sido inicialmente associada à ideia da coexistência de crenças religiosas diversas, o seu atual significado tem sido alargado de modo a abranger também a coexistência de minorias étnicas e linguísticas. ${ }^{16}$

De qualquer forma, Bobbio ensina que a tolerância não deve ser confundida com indiferença. A antítese indiferentelfanático não corresponde à antítese tolerantelintolerante. É essa, justamente, a diferença entre o tolerante e o cético. Para o segundo, não importa se a fé triunfa, enquanto que para o primeiro, o triunfo da verdade é essencial.

Segundo o mestre italiano, são diversas as boas razões da tolerância:

a) razão de prudência política: ser tolerante não significa renunciar à própria convicção, mas implica entender que "a verdade tem tudo a ganhar quando suporta o erro alheio"17. Parte-se da constatação histórica de que as perseguições, em lugar de acabar com os opositores, têm reforçado a sua existência, sendo, portanto, um ato de astúcia ser tolerante;

b) razão metodológica: a tolerância é vista como método de persuasão, sendo usada em lugar da força, da coerção ou da violência como únicos meios para alcançar o triunfo.

Por trás da tolerância entendida desse modo, não há mais apenas o ato de suportar passiva e resignadamente o erro, mas já há uma atitude de confiança na razão ou na razoabilidade do outro, uma concepção do homem como capaz de seguir não só os próprios interesses, mas também de considerar seu próprio interesse à luz do interesse dos outros, bem como a recusa consciente da violência como único meio para obter o triunfo das próprias ideias. ${ }^{18}$

\footnotetext{
${ }^{16}$ BOBBIO, Norberto. A era dos direitos, p. 203-217.

${ }^{17}$ Ibidem, p. 206.

${ }^{18}$ Ibidem, p. 207.
} 
Bobbio destaca a importância da tolerância para a garantia da convivência pacífica, assim como a sua qualidade de elemento diferenciador do regime democrático em contraposição a qualquer forma de despotismo, "uma das definições possíveis de democracia é a que põe em particular evidência a substituição das técnicas da força pelas técnicas da persuasão como meio para resolver conflitos"19;

c) razão moral do respeito ao outro: parte-se do princípio moral absoluto do respeito ao outro, "a tolerância, aqui, não é desejada porque socialmente útil ou politicamente eficaz, mas sim por ser um dever ético" ${ }^{\prime 20}$. Da aceitação desta terceira boa razão da tolerância surge o conflito entre o princípio moral da coerência que manda "pôr a minha verdade acima de tudo" e o princípio moral do respeito ou da benevolência em face do outro ${ }^{21}$, devendo o primeiro princípio ceder, na medida em que a tolerância apresenta-se como um "mal menor" em relação à obrigação moral de respeitar a liberdade interior do outro;

d) razão teórica ou da natureza da verdade: a verdade só pode ser alcançada por meio do confronto. Bobbio entende que a verdade não é uma, mas tem muitas faces. Vive-se, portanto, não em um universo, mas em um multiverso, no qual "a tolerância não é apenas um método de convivência ou de dever moral, mas uma necessidade inerente à própria natureza da verdade" 22 .

Neste ponto, discorda-se parcialmente do Bobbio. Entende-se que o mestre italiano confunde o conceito de verdade com a certeza do seu conhecimento. A verdade é uma, sendo definida como a correspondência entre o objeto/fato e aquilo que dele se afirma. A necessidade de ser tolerantes não deriva da inexistência de uma verdade, mas da incerteza sobre qual seja esta. ${ }^{23}$ Deve-se ser tolerante pela própria natureza da verdade, mas não porque há várias verdades, como defende Bobbio, mas porque, embora sendo uma, não é possível ter a certeza absoluta de que a verdade defendida seja a correta.

Essas boas razões da tolerância não impedem que possam também ser apontadas boas razões para a intolerância. As boas razões da intolerância se opõem às más razões da tolerância, sendo que, tanto a intolerância

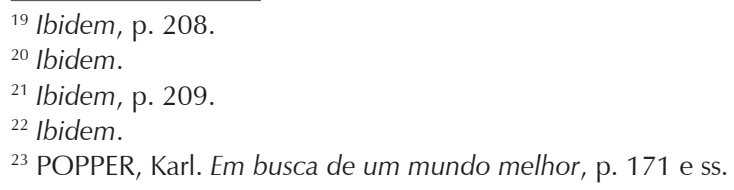


como a tolerância apresentam aspectos positivos e negativos. Assim, em um sentido positivo, uma boa razão para a intolerância é sua alusão às virtudes da firmeza, do rigor e da severidade, opondo-se à tolerância em sentido negativo, considerada "sinônimo de indulgência culposa, condescendência como um mal, com o erro, por falta de princípios, por amor da vida tranquila ou por cegueira diante dos valores" ${ }^{24}$.

Por outro lado, a intolerância em sentido negativo evita que qualquer posicionamento possa ser admitido, opondo-se, assim, à tolerância em sentido positivo, que suporta tudo.

Mas não devemos jamais esquecer que os defensores da intolerância se valem do sentido negativo para denegri-la: se Deus não existe, então tudo é permitido, De resto, foi precisamente essa a razão pela qual Locke não admitia que se tolerassem os ateus, os quais, segundo uma doutrina comum naquela época, não tinham nenhuma razão para cumprir uma promessa ou observar um juramento e, portanto, seriam sempre cidadãos em que não se podia confiar. ${ }^{25}$

Apesar de ser dominante na doutrina o posicionamento de que o único que não deve ser tolerado é o intolerante, deve-se ter presente o ensinamento de Bobbio, que afirma "responder o intolerante com intolerância pode ser formalmente irreprochável, mas é eticamente pobre e politicamente inoportuno" 26 .

A tolerância deve ser praticada, mas não como indiferença ou falsa caridade, senão como pressuposto para o diálogo capaz de estreitar os laços de solidariedade entre os membros de uma mesma comunidade.

\section{O segundo passo: dialogar para conviver}

As controvérsias em torno à tolerância são muitas e complexas, não se esgotando na identificação das suas boas ou más razões, conforme exposto no tópico anterior. Questiona-se, também, o seu campo de atuação.

Para a maioria da doutrina, o reino da tolerância é o espaço privado, na medida em que na esfera pública, o Estado intervém regulando a sociedade por meio de normas jurídicas.

\footnotetext{
${ }^{24}$ BOBBIO, op. cit. p. 210.

${ }^{25}$ Ibidem, p. 211.

${ }^{26}$ Ibidem, p. 214.
} 
Cuando el acto tolerado se convierte en derecho, no tiene sentido hablar de tolerancia. Más aún, hablar de tolerancia en el caso de un derecho reconocido en el sistema normativo básico o es una apelación innecesaria, ya que con ella se pretende superar una discrepancia deóntica inexistente, o es una señal de la ineficacia del sistema normativo básico.

[...] Por ello, la tolerancia y el derecho reconocido son conceptos que se excluyen recíprocamente. La extensión del ámbito de la tolerancia es inversamente proporcional a la vigencia de los derechos. Quien pretende ser tolerante porque respeta un derecho recubre su arrogancia jurídicomoral con el manto de una supuesta virtud benevolente. ${ }^{27}$

O problema que surge com essa distinção é a dificuldade de definir o que é o espaço público e o espaço privado. A religião, por exemplo, corresponde à esfera pública ou à privada? Quais comportamentos o Estado deve regular? Quais devem ser deixados ao campo da tolerância? É suficiente a coexistência de maiorias e minorias ou deve ser promovida a sua convivência?

São questionamentos que urge responder, na medida em que carece de sentido aceitar a diversidade, sem estabelecer mecanismos efetivos de convivência.

Nesse contexto, há autores, a exemplo de Adeno Addis, que apontam as limitações da tolerância para a construção de vínculos e instituições capazes de relacionar a todos os membros de uma comunidade política.

Toleration is seen as the bridge that links liberalism and pluralism. But, of course, a polity cannot cultivate toleration in all aspects of its life and remain a political community. There must be principles, common bonds and institutions that must have the allegiance of all members of the political community. ${ }^{28}$

Na atualidade, ensina Addis, a tolerância vem sendo considerada o preço que a maioria tem que pagar para suportar as práticas e convicções das minorias que ofendem ou são fortemente contrárias aos seus princípios, tornando-se uma espécie de falsa caridade. A prática desse tipo de tolerância esconde altos custos para as minorias, devido a qual ${ }^{29}$ :

\footnotetext{
${ }^{27}$ GARZÓN VALDÉS, Ernesto. "El sentido actual de la tolerancia", p. 43.

${ }^{28}$ ADDIS, op. cit., p. 118.

${ }^{29}$ Ibidem, p. 120.
} 
a) tolerar não necessariamente significa respeitar: a tolerância pode ser apenas um ato de indiferença, podendo chegar a ser uma espécie de "gentil não-respeito". Assim, a maioria pode ter decidido não ser necessário o Estado proibir determinada prática cultural minoritária, entretanto, pode continuar considerando tal prática como incivilizada, não sendo, portanto, levada a sério nem objeto de diálogo. Para as minorias, trata-se de uma situação ambígua, já que embora autorizadas a praticar seus costumes, não são reconhecidas como iguais,

To treat individuals with "equal respect" entails, at least partly, respecting their traditions and cultures, the forms of life which give depth and coherence to their identities. And to treat those forms of life with respect means to engage them, not simply to tolerate them as strange and alien. ${ }^{30}$

b) tolerar não promove a virtude da civilidade: não é possível desenvolver empatia com aqueles que são vistos como estranhos ou diferentes,

La auténtica civilidad no significa sonreír a los demás sin que te importe como te tratan, como si los grupos oprimidos debiesen ser amables con sus opresores. Significa, más bien, tratar a los demás como iguales, con la condición de que aquellos lo hagan también contigo. ${ }^{31}$

Para ter empatia é necessário, em primeiro lugar, ter presente que, para entender o outro, se deve antes estar preparado para dialogar com ele (dialogic engagement).

Addis afirma existirem três instituições que podem contribuir para fomentar esse diálogo:

- a escola: porque ensina o que é importante;

- a mídia: porque elabora uma imagem sobre os membros da sociedade;

- o Direito: porque define o que é aceitável.

Essas instituições "tell stories about where we have been, what is important to us, how we relate to one another, and what and who the problems are, as well as possible solutions to those problems" ${ }^{\prime \prime 2}$. Nesse sentido, as minorias devem ter acesso a essas três instituições de forma

\footnotetext{
${ }^{30}$ Ibidem, p. 121.

${ }^{31}$ KYMLICKA, Will. La política vernácula. Nacionalismo, multiculturalismo y ciudadanía, p. 261.

${ }^{32}$ ADDIS, Adeno. "Recycling in hell", p. 2259.
} 
a garantir que a informação veiculada não seja apenas uma versão da maioria, mas da comunidade como um todo;

c) tolerar equipara as minorias culturais às associações privadas: a maioria dos autores (Kymlicka, Rawls, Kukathas, etc.) defende que as minorias culturais devem adotar os valores liberais típicos das associações privadas, a exemplo do respeito à autonomia dos membros (o direito de saída - right to exit), exigência que, para Addis, poderia colocar em risco a própria existência da minoria.

Por outro lado, tratar os grupos minoritários como entes privados faz também com que seus valores sejam desconsiderados no momento de definir os valores da sociedade à que pertencem.

The complaints many cultural and ethnic minorities have against majorities is not that they are forbidden to affirm privately their convictions and commitments and the capacity to plead as special interests in the political and economic markets, but rather that they ought not seen as special, narrow, and private interest while the culture and the ethnic affiliation of the majority is viewed implicitly or explicitly as representing the general interest. ${ }^{33}$

Verifica-se, portanto, as limitações da tolerância para fomentara virtude da civilidade. É esse, justamente, o grande desafio que o Multiculturalismo não tem sabido enfrentar: afirmar a diversidade cultural da humanidade sem enfraquecer ou descartar os indispensáveis laços de solidariedade entre todos os membros de uma comunidade política (pluralistic solidarity), como forma de conferir eficácia aos direitos fundamentais.

Pienso, por ello, que todo demócrata liberal sensato debe, en el ámbito público, procurar reducir la necesidad de recurrir a la tolerancia afianzando la vigencia de los derechos fundamentales. Cuanto menos necesidad de tolerancia exista en una sociedad, tanto más decente lo será [.... . ${ }^{34}$

Daí a relevância que a proposta da Interculturalidade vem alcançando.

Constitui, portanto, tarefa impostergável de todo Estado que se autotitule democrático fomentar o diálogo entre as maiorias e as minorias da sua sociedade, por meio da regulação da escola, da mídia e do Direito, de forma a incluir a participação efetiva das minorias.

\footnotetext{
${ }^{33}$ IDEM, "On human diversity..., op. cit., p. 125.

${ }^{34}$ GARZÓN VALDÉS, op. cit., p. 45.
} 


\section{Conclusão}

O reconhecimento da diversidade cultural constitui imperativo ético indissociável do respeito à dignidade de todo ser humano, conforme o proclamado na "Declaração Universal sobre a diversidade cultural" da UNESCO. Nesse contexto, a tolerância apresenta-se como valioso mecanismo capaz de garantir a convivência pacífica entre as maiorias e as minorias de uma comunidade política.

No entanto, a tolerância apresenta limitações. A construção de um Estado democrático exige não apenas o reconhecimento e proteção da sua diversidade cultural, mas também a implementação de mecanismos especiais capazes de garantir às minorias o pleno exercício dos seus direitos fundamentais. Depois de tudo, o Estado não deve apenas garantir a coexistência, mas deve também assegurar a convivência entre todos os membros de sua sociedade.

Para tanto, o Estado deve promover o diálogo entre as maiorias e as minorias, mas não qualquer diálogo, senão um que seja informado, neutral e de livre e igualitário acesso a todos os membros da sociedade. Nesse âmbito, três instituições apresentam-se como chaves: a escola, a mídia e o Direito, devendo, portanto, serem reguladas pelo Estado de forma a contribuírem na construção de uma sociedade pluralmente solidária.

No século XXI, a humanidade ainda tem a chance de superar os erros do passado. É com essa preocupação que se propõe não apenas o reconhecimento/respeito do outro, mas a necessidade de promover a interação dialógica entre as diversas culturas, pressuposto do próprio engrandecimento da humanidade.

\section{Bibliografia}

ADDIS, Adeno. "On human diversity and the limits of toleration", in SHAPIRO, Ian; KYMLICKA, Will. Ethnicity and group rights. New York: New York Universities Press, 1997, p. 113-153.

. "Recycling in hell", in Tulane Law Review, New Orleans, v. 67, 1993, p. 2253-2266.

ALVARADO, Virgilio. "Políticas públicas e interculturalidad", in FULLER, Norma (ed.). Interculturalidad y política. Lima: Red para el desarrollo de las ciencias sociales en el Perú, 2003. 
BBCBrasil. Nobel se desculpa por declarações sobre inteligência negra. Disponível em: www.bbc.co.uk/portuguese/reporterbbc/story/2007/10/07 1019geneticista desculpa_fp.shtml. Acesso em: 08.01.2012.

BOBBIO, Norberto. A era dos direitos. Rio de Janeiro: Campus, 1992.

BOBBIO, Norberto; MATTEUCCI, Nicola; PASQUINO, Gianfranco. Dicionário de política. Brasília: Universidade de Brasília, 1986.

BOSSUET, Jacques-Bégnine. Discurso sobre la historia universal. T. II. Madri: Compañía General de Impresores y Libreros, 1842.

ELBAZ, Mikhaël. "El inestimable vínculo cívico en la sociedad-mundo", in ELBAZ, Mikhaël; HELLY, Denise, op. cit.

ELBAZ, Mikhaël. HELLY, Denise. Globalización, ciudadanía y multiculturalismo. Granada: Maristán, 2002.

FULLER, Norma. "Introducción", in FULLER, Norma (ed.). Interculturalidad y política. Lima: Red para el desarrollo de las ciencias sociales en el Perú. Lima: 2003.

GARZÓN VALDÉS, Ernesto. "El sentido actual de la tolerancia", in GIUSTI, Miguel. Tolerancia: el estado de la cuestión. Lima: Fondo Editorial de la Pontificia Universidad Católica del Perú, 2010.

ISÓCRATES. Discursos. 2 v. Madri: Gredos, 1979.

KYMLICKA, Will. La política vernácula. Nacionalismo, multiculturalismo y ciudadanía. Barcelona: Paidós: 2001.

. Ciudadanía multicultural. Barcelona: Paidós, 1996.

LOCKE. John. Carta sobre a tolerância. Lisboa: Edições 70, 2000.

ONU. Pacto internacional sobre os direitos civis e políticos. Disponível em: www. dhnet.org.br/direitos/sip/onu/doc/pacto2.htm. Acesso em: 05.01.2012.

PÁDUA, Marcílio de. O defensor da paz. Petrópolis: Vozes, 1995.

POPPER, Karl R. Em busca de um mundo melhor. Lisboa: Fragmentos, 1989.

RAYNAULD, Philippe; RIALS, Sthephane. Diccionario Akal de Filosofía Política. Madri: Akal, 2001.

REMILLARD, Gil. "Les droits des minorités", in Atas da /l Conferência Internacional de Direito Constitucional. Quebec, 5-8 de março de 1986.

SANTOS, Boaventura de Sousa; NUNES, João Arriscado. Introdução: para ampliar o cânone do reconhecimento, da diferença e da igualdade. Disponível em: www. ces.fe.uc.pt/emancipa/research/pt/ft/intromulti.html. Acesso em: 01.02.2012.

SCHMITT, Carl. O conceito do político. Petrópolis: Vozes, 1992.

SEMPRINI, Andréa. Multiculturalismo. Bauru: EDUSC, 1999.

TUBINO, Fidel. "Entre el multiculturalismo y la interculturalidad: más allá de la discriminación positiva", in FULLER, Norma (ed.) Interculturalidad y política. Lima: Red para el desarrollo de las ciencias sociales en el Perú. Lima: 2003. VOLTAIRE. Tratado sobre a tolerância. São Paulo: Martins Fontes, 1993. 


\section{Abstract}

\section{From coexistence to living together with the other: between multiculturalism and interculturalism}

For centuries, Homer said it was civility that distinguishes men from animals. The Cyclops, said the Greek poet, were considered wild monsters not because they practiced navigation, but because they ignored the hospitality. Today, more than twenty centuries later, Interculturality aims to rescue the virtue of civility as a way to guarantee the peaceful coexistence of majorities and minorities, and overcoming the limitations of Multiculturalism and its defense of tolerance. In this context, our objective is to defend the virtue of civility as a precondition for the effective guarantee of fundamental rights of all members of a multicultural society.

Keywords: Tolerance; Multiculturalism; Interculturality; Minorities; Civility.

Recebido para publicação em 25/03/2012.

Aceito para publicação em 07/05/2012.

Received for publication in March, 25 ${ }^{\text {th }}, 2012$.

Accepted for publication in May, $7^{\text {th }}, 2012$. 